Journal of Emergency Primary Health Care

An International elournal of Prehospital Care Research, Education, clinical Practice, Policy and Service Delivery

ISSN 1447-4999

\title{
EDITORIAL
}

Article 990186

Revision of the Joint NHMRC/AVCC

Statement and Guidelines on Research Practice

\section{Frank Archer}

The National Health and Medical Research Council (NHMRC) and the Australian Vice Chancellors' Committee (AVCC) are in the process of revising their jointly authored "Statement and Guidelines on Research Practice" (1997), http://www.nhmrc.gov.au/ funding/policy/reseachprac.htm. This 1997 publication serves as the pre-eminent guidelines on good research practice in the Australian context. A valuable companion resource, as an example of the application of these principles to underpin good research practice in the clinical setting is, "The Guide to Good Research Practice", prepared by the Department of Epidemiology and Preventive Medicine at Monash University, http://www.med.monash.edu.a u/epidemiology/publications/grpg2003.pdf .

In August 2003, the NHMRC/AVCC commenced a process to review their 1997 statement and published a Consultation Draft \# 1, under the title "The Australian Code for Conducting Research 2004”. (December, 2004), http://www.nhmrc.gov.au/funding/policy/code.htm. Following input received in response to this first draft of the revised Code, the NHMRC/AVCC has now released a second consultation draft, the "Australian Code for the Responsible Conduct of Research” (February 2006), http://www.nhmrc.gov.au/funding/polic $\mathrm{y} /$ code.htm. When finalised, this document will replace the earlier 1997 document. The Code is intended to be used as the standard for responsible conduct of research in Australia.

This consultation process will be of interest to all readers of JEPHC, be you a researcher, clinician, administrator, policy developer, or student, as it brings the opportunity to:

1. be updated on the national thinking with respect to the defining standards for the responsible conduct of research in Australia; and,

2. prepare a submission and make a contribution to the evolution of this Code, which will ultimately govern good practice in Australian research.

The second consultation draft is more extensive than the 1997 statement and includes a definition of "Research". It commences with an outline of the general principles that underpin the responsible conduct of research. The remainder of the second consultation draft focuses on the "practices for encouraging responsible research conduct" and addresses issues such as: research data and records management; supervision of students and research trainees; publication and dissemination of research findings; authorship; peer review; conflicts of interest; collaborative research; and, handling allegations of research misconduct. The document is not aimed at reviewing or producing guidelines on specific research 
methodologies, rather it sets the framework for encouraging, the conduct of responsible research for Australian research in general.

The document is essential reading for researchers in emergency primary health care and also for those who fund, support, supervise, or benefit from research conducted in this environment. A number of chapters have a direct bearing on the editorial policies of JEPHC and, once finalised, will be incorporated in the JEPHC guidelines at the earliest opportunity. As the research profile of emergency primary health care continues to grow and expand, we would be well advised to incorporate this emerging Australian Code into our research practice from the earliest possible time. 